\title{
Calibrate to innovate: Community age vectors and the real time incrementation of language change
}

\author{
S O P H I E H O L M E S - E L L I O T T \\ University of Southampton, $U K$
}

A B S T R A C T

This study investigates children's real time incrementation of language change as it is impacted by community-wide patterns of linguistic variability. The investigation combines apparent time analyses across an age-stratified sample of adult speakers, with real time analyses across a panel of speakers spanning childhood to adolescence. Three variables are analysed: GOOSEfronting, a socially unmarked change; TH-fronting, a socially stigmatised, rapidly expanding change; and T-glottaling, a socially stigmatised, steadily shifting change. Variables are selected based on their social and generational profiles which present learners with more or less challenging community patterns to extract. Real time analyses confirm that community variance impacts on speakers' ability to increment change in real time. Findings provide support for the momentum-based model of language change and builds on Labov's (2012:267) theory of the 'outward orientation' of children, which views learners as capable of extracting age vectors from generational differences. (Language change, incrementation, real time, GOOSE-fronting, TH-fronting, T-glottaling)*

\section{N T R O D U C T I O N}

From the moment they start to acquire language, children are faced with linguistic variation. An integral part of language acquisition involves children coming to understand variable features so that they may learn to process, interpret, and ultimately utilise them in their own speech. But young speakers do more than reproduce the patterns of the ambient speech community; they are also the agents of change. Sociolinguistic research reliably demonstrates that ongoing language change is led by adolescent and young adult members of the speech community where 'successive cohorts and generations of children advance change beyond the level of their caretakers and role models' (Labov 2007:346). The process of children overtaking their parents underpins the incrementation model of language change. This model describes the process of 'vernacular reorganisation' (Labov 2007:346) where young speakers reorganise their systems in line with the ongoing trends in the community over the developmental course between 
childhood and adolescence. If a vowel is shifting, or a new consonantal realisation is replacing a traditional one, children will gradually shift their linguistic systems in the direction of the innovation until they reach the leading edge of the change. At this point their systems stabilise, usually during late adolescence or young adulthood. However, as Labov (2012:276) notes, while we may observe each wave of young speakers moving into the leading position, exactly How children know to do this is somewhat of a mystery:

The study of change in progress shows children learning to talk from their parents, then learning to talk differently from their parents, and then even more mysteriously, continuing such differences in the same direction.

How do children identify variables as changes? And, how do they know the direction, and magnitude, in which to shift their rates so that they move into the leading position? Recent work has called on a momentum-based learning approach which sees children as community-oriented agents of change. This model adopts Labov's (2012:267) concept of the 'outward orientation' of children who 'respond to differences in the use of linguistic variables across age-groups' (Bermúdez-Otero 2020). In this view, young speakers look to patterns in the community and adjust their rates accordingly: 'children are keen observers of vectors within the speech community... actively looking to those just a little older than themselves as models' (Sankoff 2019:22122). The momentum-based account suggests that, during the incrementation of change, children use the extracted vectors of age-based patterns to situate themselves at the leading edge so that they continue community changes in the same direction.

This article examines the momentum-based theory through a real time investigation of the incrementation of language change. Specifically, it explores the relationship between variable patterns in the adult community and the linguistic changes made by young speakers across their early life-spans. This is achieved through a comparison of the real time shifts made by a panel of young speakers, with apparent time patterns across an age stratified adult corpus. These perspectives are combined across three different variables that differ to the extent to which they provide clearer, or more obscured, age vectors from the perspective of the active learner. The momentum-based theory predicts that changes with clearer vectors should be easier for young speakers to interpret, which in turn will impact on their ability to adjust their systems towards the innovative target and successfully increment change. The subsequent analysis indicates whether these predictions are borne out by the data. In order to situate the analysis, I present an overview of research into the early sociolinguistic life course.

\section{B A C K GR O U D : THE E A R L Y S O C I O L I G U IS T I C L IF E C O R S E}

Sociolinguistic research indicates that adolescent and young adult speakers are the most innovative members of their speech communities. When change is charted 
through apparent time, the normal pattern is an inverse relationship where the rates of an innovative form go up, as the average age goes down. However, when children are added to the view, this pattern is disrupted as they are shown to lag behind the leading adolescents. This creates an 'adolescent peak' in apparent time (Labov 2001:455), schematised in Figure 1.

Adolescent peaks are 'a consequence of a mechanical linguistic process, which concludes at the critical age of vernacular stabilisation' (Kirkham \& Moore 2013:278). Peaks have been shown in apparent time across a range of dialects, feature types, and have been found in the generational trajectories of men and women irrespective of which gender is leading the change (Labov 2001; Tagliamonte \& D'Arcy 2009; Holmes-Elliott 2016). Tagliamonte \& D'Arcy (2009:100) describe the adolescent peak as a 'general requirement of synchronic change'. In other words, when children are included in the apparent time view, they will show more conservative rates than the adolescents on the forefront of change. As children mature, they gradually shift their linguistic systems towards the innovative edge of ongoing changes within their communities until they become the leaders: this is the incrementation of language change. In a review of research, Sankoff (2019) observes that the process of incrementation as the driving force of language change 'has been confirmed empirically'. Kerswill (2010:244) echoes this sentiment and notes:

'The study of dialect transmission holds the key to the mechanism of change: it is adolescents, who do the 'work' (Eckert 2000), not, as historical linguists have supposed, young children who fail to learn their parents' language properly (Aitchison 1981:180).

The juvenile lag has been explained through a shift in target model that children experience as they grow up. As research into the development of sociolinguistic competence demonstrates, initially children match and model the relatively conservative input they receive from their parents and guardians. Studies show caregivers transmit complex patterns of both linguistic and social variation via child directed speech (CDS), which their children replicate in their own speech (Roberts \& Labov 1995; Roberts 1997; Foulkes, Docherty, \& Watt 2005; Smith, Durham, \& Fortune 2007). In an early study of this type, Roberts' (1999) examined the CDS of caregivers of eighteen- to nineteen-month-old toddlers in Memphis. In her examination of rates of (ay)-glide reduction, where, for example, night or light are realised as [na:t] or [la:t], she found marked reduction in use of the local monophthongal form in the CDS of the caregivers compared to their adult directed speech. Foulkes and colleagues (2005) reported a similar finding from their investigation of CDS in the northeast of England. They examined the rates of intersonarant $/ t /$ that may be variably realised as standard oral stop (canonical $[\mathrm{t}]$ ) or as a glottally reinforced variant (variably represented as [?t] or [t?]), a highly salient and stereotypical form of northeast England. They found lower rates of the local form in the CDS of the caregivers compared to inter-adult speech, as well as higher rates among mothers of older children compared to mothers of younger children. Foulkes and colleagues (2005:198) 


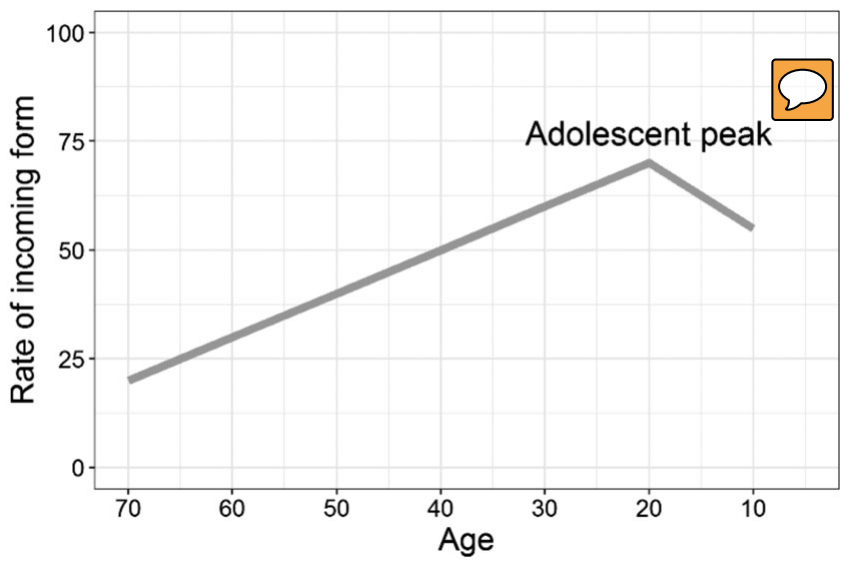

FIGURE 1. Schematised representation of adolescent peak in apparent time, based on Labov (2001:449).

interpret the caregivers' behaviour as a teaching strategy where they modify their speech to prime the children to socially meaningful linguistic structure.

In this view, CDS provides a template that young learners use to scaffold their own developing awareness of the sociolinguistic meaning of linguistic variables. Labov (2001:437) suggests that the mechanism of acquisition is through association: 'linguistic variation is transmitted to children as stylistic differentiation on the formal/informal dimension... formal speech variants are associated by children with instruction and punishment, informal speech with intimacy and fun'. In their study of unmonitored caregiver and child speech in northeast Scotland, Smith and colleagues (2007) tested Labov's hypothesis directly. They (2007:75) analysed a highly salient local stereotype, $[\mathrm{u}:]$ for $[\Lambda \mathrm{t}]$ (e.g. house sounds like hoose) and found higher rates of the local form in caregiver speech uttered during play and routine compared to that spoken during discipline or teaching. What is more, this pattern was matched and replicated in the children's speech.

While CDS patterns provide a blueprint for sociolinguistic variability, these early interactions are just the beginning. Although young children may be exposed to a variety of overheard talk, within a typically Western child-rearing environment, the dominant interlocutor is the primary caregiver. Moreover, while parent-child talk provides a vital scaffold, as shown above, CDS presents the child acquiring language with a conservative model. As they grow up, the level of variability children encounter increases dramatically as they are exposed to an increasing variety of different systems. For the child this creates a steadily more challenging sociolinguistic environment; they can no longer simply mirror the shifts of their main interlocutor. In order to become 'fully fledged members of the adult speech community' (Romaine 1984) children also need to be able to 
modify their production independently. In other words, they must acquire an adultlike level of sociolinguistic, or communicative, competence (Ervin-Tripp 1972; Romaine 1984; Kerswill \& Williams 2000; Díaz-Campos 2011).

The acquisition of an internalised system of sociolinguistic competence goes hand in hand with expansion of the social world of children and the development of their speech repertoires: 'social constraints are learned by interacting with a variety of people... The opportunities for these types of interactions would naturally increase as one grew older' (Roberts 1994:176). This expansion usually takes the form of entering formal education. In an investigation of young Spanish speakers, Díaz-Campos (2005:61) found that children aged 4:5-5;9 years old exhibited style shifting of socially marked forms while younger children aged 3;5-4;4 did not. Díaz-Campos (2011:272) attributed this to the time they had spent at school, arguing that older children had had longer exposure to more formal styles of speech and greater opportunity to internalise the community norms. Similarly, in an early study of school children in Edinburgh, Romaine (1984:102) charted the acquisition of style shifting and observed that 'older children have restricted their use of the Scots forms to more casual domains while the younger children have not yet acquired this ability to contextualise the variants they use'. Chevrot, Beaud, \& Varga (2000:301-302) show a similar pattern in their study of young French speakers. In an analysis of word final $/ \mathrm{r} /$, they found that while younger children had acquired the linguistic constraint (higher rates of deletion before a consonant), only the older children showed higher retention in the more formal context.

A review of the evidence so far suggests that the early lifespan is characterised by a period of sociolinguistic profiling and compiling which becomes steadily more challenging as the child's social sphere expands. During this time, children must come to recognise and integrate a variety of different speaker templates: the conservative model of their parents, the formally endorsed code of their teachers, as well as the playground appropriate lects of their peers. The range of speaker templates and interactional situations enable young speakers to interpret the social meanings of variable features. They come to realise that some forms, for example, glottal stops, or local vocalic variants, are perfectly acceptable in the schoolyard but not suitable for the classroom. This development of an internalised monitor is accompanied by increased stylistic proficiency: "children slowly gain sociolinguistic maturity in a manner that involves a gradual increase in the number of styles that are perceived and treated in an adult way' (Kerswill \& Williams 2000:105).

At the same time as developing socially evaluative associations, young speakers are also necessarily compiling age-based associations. Kerswill \& Williams (2000:94) emphasise the role of the similarly aged peer group in their study of young speakers from Milton Keynes. In the adoption of innovative forms of the rapidly levelling [ou] vowel, they report that 'peer-orientation seems to override all other factors'. Children who scored high on the innovative index were 'sociable and often cited as friends by other children. By contrast, the low scorers are somewhat distanced from their peers' (Kerswill \& Williams 2000:94). In a study of a 
range of stigmatised forms, Díaz-Campos (2011:265) found that children from lower socioeconomic backgrounds converged towards the more standard norm of the children from higher socioeconomic backgrounds. He argues that both influences, standard and peer norms, are present and can work in combination. Indeed, Díaz-Campos' findings suggest that despite its strong influence, the peer group does not exist in a social vacuum; young speakers must also look to communitywide patterns to infer the value of linguistic variants.

The challenge faced by children as they compile the social-evaluative and age associated patterns of linguistic variation is further complicated by the presence of ongoing language change. As noted by Roberts (1997:247), variables in the process of change present young speakers with a 'moving target'. Language change creates a situation where children must conform to some community norms by becoming adept at adult-like patterns of style shifting whilst simultaneously violating others by becoming the leaders of change. While the start of school may explain the shift in linguistic alliance from family to friends, and increased proficiency in style shifting, the question remains as to how, and why, children know to increase their rates of incoming forms beyond the most innovative speakers. According to the momentum-based learning theory of language change, in the same way children build representations of linguistic variability which include social-evaluative based associations on a formal-informal dimension, they analogously do this for age-based associations on an older-younger dimension.

[T] he learner's knowledge of the community norm comes to include an age vector: in other words, children and adolescents acquire a mental representation of the differences in variable use between age-groups in their community. (Bermúdez-Otero 2020)

As Sankoff (2019:222) suggests, 'children are alive to the vector': similar to the way they use the social-evaluative associations to inform their style shifting behaviour, they use the age-based links to set their levels of incoming forms as they increment change. From their interactions with a range of differently aged speakers - grandparents and elderly relatives, parents and teachers, to older peers and younger children - the trajectory of change becomes evident. By computing the vectors, young speakers carry out their own personal apparent time assessments of age-based variability. During incrementation, they alter their systems and situate themselves accordingly so that the change continues in the same direction it has been for generations. Viewed in this way, incrementation is not an example of children breaking community rules, but rather following them. By incrementing change, children obey the diachronic norm, just as they obey the social norm by replicating the style shifting behaviour of the broader community.

This article examines the momentum-based theory empirically through an investigation of how community-wide patterns of variability impact on the variable production of young speakers. The overarching aim is to investigate how successfully children can parse both age-based, and social-evaluative based, patterns of variation in order to inform their own variable productions. Their productive success is 
gauged by both their ability to increment change: do they show real time increases in their use of innovative forms? And also their stylistic proficiency: do they show style shifting in line with the community pattern? This is carried out through a comparative analysis of a range of variables across real and apparent time trajectories of change. The variables were selected on account of their differing social and agebased profiles. In line with the momentum-based model, these changes present the young speakers with harder or easier vectors to extract. A detailed account of the individual variables is provided in the following section.

\section{E T H O D O L O G Y}

\section{Community and data}

The data come from Hastings, a coastal town about sixty miles south of London, situated within the wider Southern British English dialect area. For the purpose of the present study, there are two sample populations: an age stratified apparent time sample and a real time panel of young speakers. All participants are monolingual speakers of English, born and raised in Hastings and have not lived outside of the area for any significant length of time. Where possible, parents and spouse are also born and raised in the area. The apparent time sample consists of thirty-seven speakers across four age groups with an approximately equal gender split (see Table 1).

The real time sample consists of the youngest cohort from the apparent time sample. Participants were initially interviewed in 2012, and then again four years later in 2016 (see Table 2).

\section{Data collection and processing}

For the adult participants in the apparent time sample, data were gathered using traditional sociolinguistic interviews (Labov 1984) either solo with only the interviewer, or in pairs with the interviewer and a family member. Data collection from the real time sample took place at school. For the first set of interviews the participants were interviewed at school during school hours in friendship pairs. At this point the participants were enrolled at a local primary/elementary school. The second set of interviews matched the procedure of the first as closely as possible: interviews were conducted at school (now secondary/high school), during school hours, and in friendship pairs. However, unlike the first set of interviews, the second set was arranged around three different speech activities so as to provide a range of stylistic contexts. The participants first read a short passage, followed by a sociolinguistic interview with the researcher (matching the original, primary school interviews), for the final stage, the researcher left the room and the participants engaged in unmonitored conversation. All data were recorded on a solid state recorder using a sampling rate of $44.1 \mathrm{kHz}$. Interviews were orthographically transcribed using Transcriber (Boudahmane, Manta, Antoine, Galliano, \& Barras 2008). 
TABLE 1. Apparent time sample structure.

\begin{tabular}{llll}
\hline \hline Age group & Age range & Male & Female \\
\hline Older & $63-91$ & 4 & 4 \\
Middle & $34-51$ & 4 & 4 \\
Young & $15-17$ & 4 & 4 \\
Children 2012 & $9-11$ & 5 & 8 \\
\hline \hline
\end{tabular}

TABLE 2. Real time panel sample.

\begin{tabular}{lccc}
\hline \hline Time point & Age range & Male & Female \\
\hline Children 2012 & $9-11$ & 5 & 8 \\
Children 2016 & $13-15$ & 5 & 8 \\
\hline \hline
\end{tabular}

\section{Analysis: The variables}

The aim was to investigate the relationship between community patterns of variation and change across apparent time, and the real time shifts young speakers make between childhood and adolescence. It was therefore necessary to select changes with a range of social and age-based profiles. Three variables were selected: GOOSE-fronting, TH-fronting, and T-glottaling. The first change, GOOSEfronting, is a socially unmarked change that generally operates below the level of consciousness. It is hypothesised that this form should provide the clearest picture as learners do not need to disentangle stylistic variability from generational variability. In this case, the task of incrementing the change should be relatively straightforward, the speakers need only to interpret the age-based variability and adjust their rates in line with the wider community trend. For the remaining features, $\mathrm{TH}$-fronting and T-glottaling, the task is harder as both forms exist above the level of consciousness: they are stigmatised and exhibit style shifting. This creates a situation where young speakers will need to interpret variability along multiple dimensions: style and age. However, these features progress at different rates; $\mathrm{TH}$-fronting is a rapidly expanding innovation, while $\mathrm{T}$-glottaling shows steady expansion. With regards to the age vector, rapid changes present stark generational differences and therefore clearer age vectors than steadily progressing changes. Based on these differing profiles, the variables can be placed on the following cline from easiest to hardest to interpret from the patterns of variation in the community (see Table 3).

TABLE 3. Difficulty cline of variable community pattern.

\begin{tabular}{lcr}
\hline \hline Easier & $\leftrightarrow$ & Harder \\
\hline GOOSE-fronting & TH-fronting & T-glottaling \\
\hline \hline
\end{tabular}


The real time speakers' success will be evaluated in a number of ways:

(i) The PATterning of the Group ACROSS REAL time. This assesses whether the speakers increment in the right direction at a group level.

(ii) The PATterning OF the INDividuals aCross REAL time. This assesses the extent to which the individuals move in parallel across real time and evaluates whether they have a shared diachronic norm.

(iii) The StYLE ShIFTing ACross THE STIGMATISED FORMs. This assesses whether the speakers have acquired the social evaluation of the form.

\section{A N A L Y S IS A N D R E S U T S}

\section{Statistical analysis}

The data were modelled using a series of mixed effects models: linear mixed effects regressions (lmers) for the continuous variable GOOSE-fronting, and generalised linear mixed effects regressions (glmers) for the binary variables $\mathrm{TH}$-fronting and T-glottaling. Fully saturated models were built containing all fixed factors and their interactions using the 'lmer' or 'glmer' function of the lme4 package (Bates, Maechler, Bolker, \& Walker 2015) in R (R Core Team 2018). Final models were derived by using the 'drop1' function of LmerTest package (Kuznetsova, Brockhoff, \& Christensen 2016) to eliminate nonsignificant factors and their interaction terms (cf. Raymond, Brown, \& Healy 2016). Final model selection was also informed through comparison of Akaike information criterion (AIC) and Bayesian information criteria (BIC); where different models showed similar performance, simpler models were selected over more complex ones. Post hoc within factor contrasts were carried out using estimated marginal means, henceforth EMMs (also known as least squares means; Lenth 2017), with results Tukey method corrected for multiple comparisons.

\section{Data structure and modelling}

Due to the range of data structures, a series of models were built during the analysis of each variable.

(i) An APPARENT timE MODEL. This model included all four cohorts of the apparent time sample (older, middle aged, young, and child speakers from the 2012 recordings). It is used to establish whether the variable is changing within the community, the speed at which the change is progressing, and also serves to test for presence of a significant 'adolescent peak'. Speaker and word are included as random intercepts.

(ii) A REAL time MODEL. This model is used to test whether the real time cohort has changed significantly across the two time points, and further, whether they have shifted in the predicted direction. Speakers are entered into these models as a random intercepts as well as random slopes across the two time points.

(iii) A STYLE MODEL FOR THE 2016 DATA. This model was built to test the effect of stylistic context in the 2016 data. Speaker and word are included as random intercepts. 
Unless stated, all reported $p$-values derive from final models that appear in the appendices. The analysis of each variable is preceded by a short outline of the feature.

\section{GOOSE-fronting}

The GOOSE vowel encompasses 'those words whose citation form in RP and GenAm has the stressed vowel /u(:)/' (Wells 1982:147). GOOSE-fronting (or /uw/-fronting, e.g. Labov 2001) refers to the process where the high back rounded vowel shifts gradually forward in the vowel space over time so its realisation may more accurately described as a phonetically central or even front vowel (Catford 1988:128). The change has been observed in a wide range of distinct varieties of English. It has been reported in dialects throughout England (Tollfree 1999; Altendorf \& Watt 2008; Cheshire, Kerswill, Fox, \& Torgersen 2011), the United States and Canada (Clarke, Ford, \& Amani 1995; Fought 1999; Labov 2001; Fridland 2008), South African English (Mesthrie 2010), as well as Australian and New Zealand English (Cox 1999; Easton \& Bauer 2000). The change is so widespread that it is probably more unusual to find a dialect in English that does not exhibit GOOSE-fronting. It can occur in a range of checked environments (moon, spruce, route) as well as unchecked (too, glue, few). Although variable across dialects, GOOSE-fronting is frequently preceded by palatal approximant yod environments in British English (news, tune, beauty; Wells 1982:147). Indeed, fronting is strongly conditioned by linguistic factors where frequently occurring environments are described as promoting, or driving, the change (e.g. Stockwell \& Minkova 1997). Social factors, where they do occur, often pale in comparison to linguistic ones (e.g. Hall-Lew 2011). The change is generally not subject to public commentary, nor does it exhibit strong associations with any social groups (Fridland 2008; Haddican, Foulkes, Hughes, \& Richards 2013). Investigations of the change generally do not report style shifting. In sum, GOOSEfronting is a phonetically gradual change that is not prestigious or stigmatised, nor associated strongly with a class or speaking style. It should therefore provide a clear age vector to young speakers incrementing the change in real time.

\section{GOOSE-fronting analysis}

In line with previous analyses, and owing to the phonetically gradual nature of GOOSE-fronting, this feature is analysed acoustically through measurement of the second formant (F2). Following transcription, recordings were automatically aligned and vowel measures extracted using FAVE-align (Rosenfelder, Fruehwald, Evanini, Seyfarth, Gorman, Prichard, \& Yuan 2014). The forced-alignment was hand-checked and misaligned elements manually corrected. The data were normalised using Lobanov (1971) scaling and converted back into Hertz. This method was selected as Kohn \& Farrington's (2012:2247) comparative review of normalisation techniques revealed that Lobanov performed best at preserving meaningful sociolinguistic differences across longitudinal child data. All preceding and following 
phonological contexts were included in the analysis with the exception of coda /1/ environments (e.g. cool, school, tool) which has been shown to inhibit, or even block fronting in most dialects (e.g. the GOOSE/GHOUL split, Wells 1982; Labov 1994).

\section{GOOSE-fronting: Apparent time}

The final apparent time model (see Appendix A) includes age as a categorical fixed factor whilst accounting for preceding environment and the potential for these factors to interact. Following a more articulated coding schedule, preceding environment was collapsed into a three-part system: palatals (you, few, etc.), coronals (toot, shoot, etc.), and noncoronals (goose, boot, etc.). Gender was included initially but was not significant and therefore eliminated. Modelling showed that preceding environment significantly interacted with age indicating that the patterning is not consistent across the age cohorts as illustrated in Figure 2.

While the first three age cohorts demonstrate a similar hierarchy across preceding environment (palatal $>$ coronal $>$ noncoronal), this effect weakens across time. Further, the child cohort do not replicate the dominant pattern. Post hoc EMMs confirm the visual patterns: for the older speakers, palatal estimates are significantly higher than coronals $(p=.03)$ and coronals significantly higher than noncoronals $(p<.0001)$. This is also the case for the middle-aged cohort (palatals - coronals: $p=.0025$; coronals - noncoronals: $p=.019$ ). However, none of the within factor contrasts are significant in the young speaker data. For the child data, while coronals are significantly higher than noncoronals ( $p$ $=.03)$, palatal environments are significantly LOWER than coronals $(p<.0001)$. In sum, similar to previous accounts of the change (e.g. Harrington, Kleber, \&
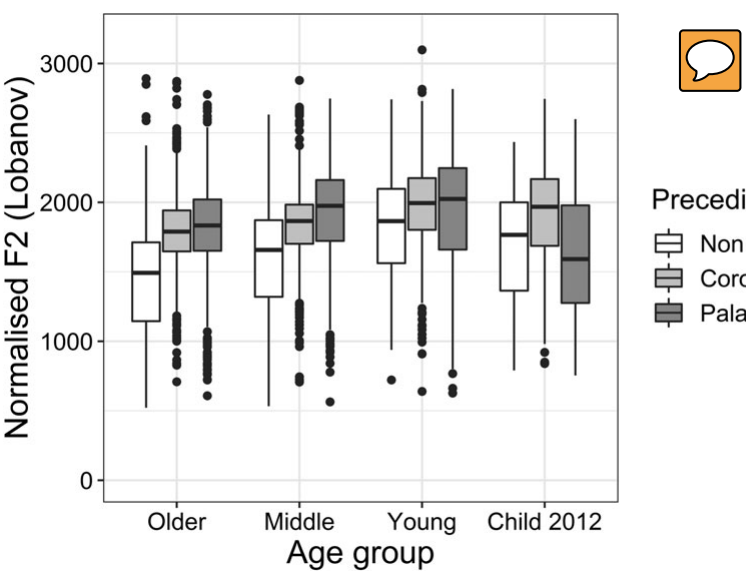

FIGURE 2. GOOSE-fronting: preceding phonetic environment across apparent time. 


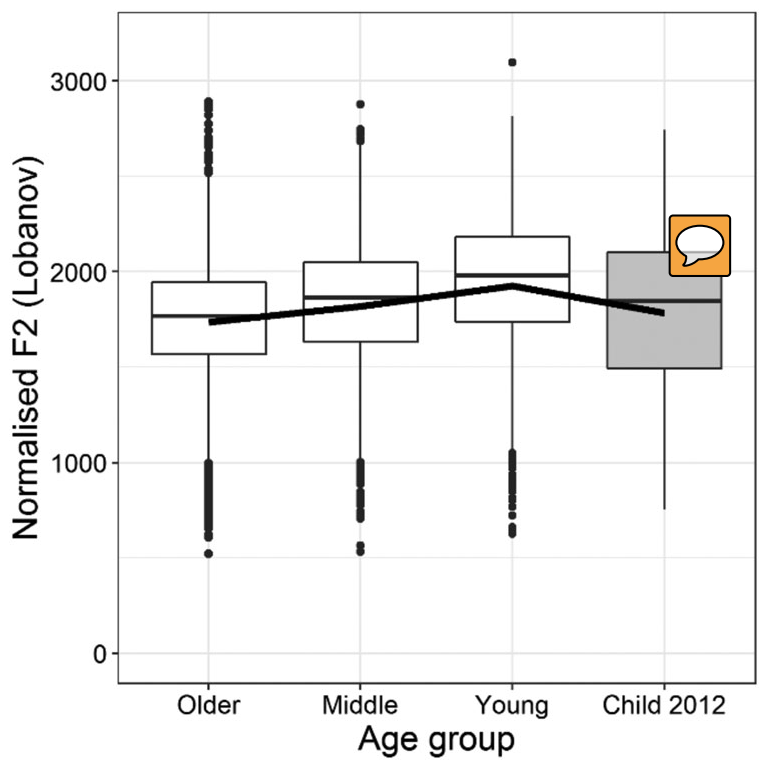

FIGURE 3. GOOSE-fronting: apparent time.

Reubold 2008; Baranowski 2017), the phonological conditioning weakens over time. The upset of the patterning in the child data may indicate the emergence of a different pattern, or it may be a temporary fluctuation in the data which resolves itself over time as the children acquire the majority pattern; the real time analysis sheds light on this question.

Alongside the differences in conditioning, there is also a clear shift in the average target across the generations. Figure 3 reflects the age pattern shown in the model estimates: a steady monotonic increase in F2 across the three adult age cohorts as well the predicted adolescent peak caused by the children's lower F2 values. Comparison of EMM's, revealed that this peak is statistically significant where the young speakers showed higher estimates than the middle-aged speakers $(p=.03)$, and also the children $(p<.0001)$. While the apparent time perspective provides indirect support for the incrementation model of language change, longitudinal evidence is necessary to confirm this; do the children shift their GOOSE targets towards the leading edge of the change as they approach adolescence?

\section{GOOSE-fronting: Real time}

The final real time model (Appendix B) selected age and preceding environment as fixed factors; gender was not significant nor were any interactions. As displayed in Figure 4, Speakers' average F2 significantly increases over time indicating that the 

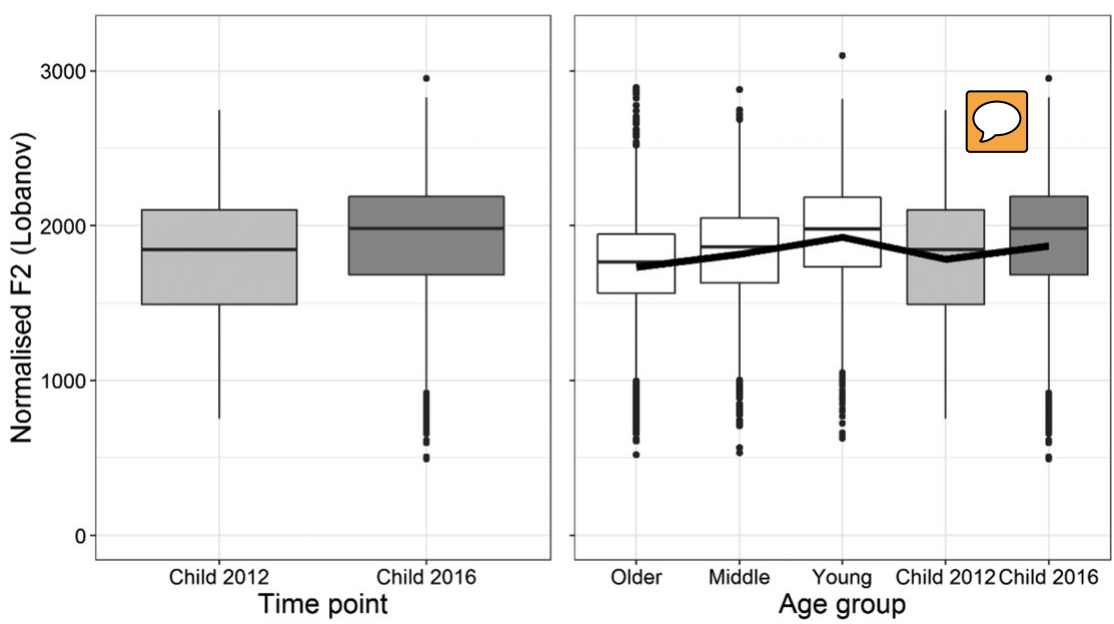

FIGURE 4. GOOSE-fronting: real time and apparent time.

GOOSE target moves significantly forward in real time. The left panel shows solely the real time data while the right panel contextualises the real time shift within the apparent time perspective. The real time speakers are behaving as predicted; where they showed a significant lag in the apparent time view of the data, they now show a significant increase. As adolescents, these speakers have not yet moved into the leading position within the community, but they are on their way.

While the aggregate pattern shows the predicted uptick over time, the apparent time model indicated that the children did not show the same constraint hierarchy for the phonetic conditioning. The real time model reports that age did not significantly interact with phonetic environment, which indicates that there is no statistically significant change in the constraint hierarchy between the time points. However, while there is no significant change, Figure 5 illustrates the visible trend.

While the hierarchy remains the same between 2012 and 2016 (coronal $>$ noncoronal $>$ palatal), the constraint diminishes over time with smaller differences between the averages in 2016 compared to 2012. In essence, while the pattern is still slightly out of step compared to the older and middle-aged speakers, the real time adolescent speakers now resemble more closely the young apparent time speakers. This observation aligns well with previous accounts of the change that report a weakening of the phonetic conditioning over time. It appears that just as they do with the overall target, the children also look to the community for the patterning of the constraints and to adjust their underlying variable systems in line with the broader trend. 


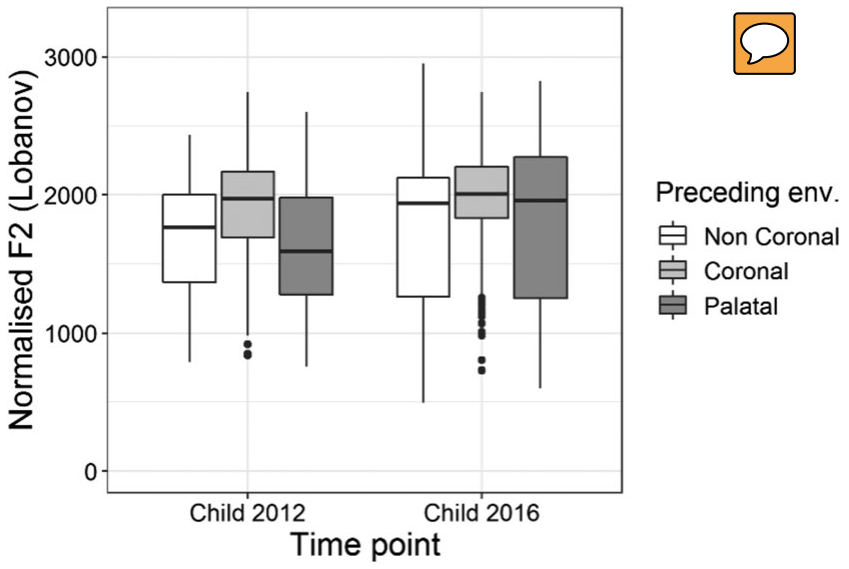

FIGURE 5. GOOSE-fronting: preceding phonetic environment across real time.

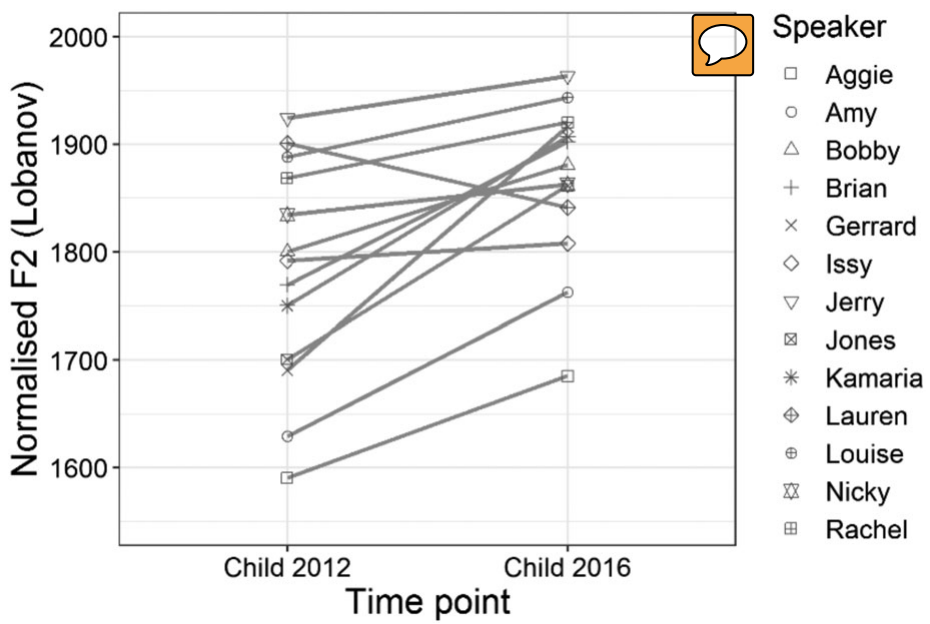

FIGURE 6. GOOSE-fronting: individual trajectories across real time.

The real time averages show a move towards the innovative edge of the change. However, from the aggregate data it is not possible to tell whether this is the case for all speakers. It may be that a few highly innovative individuals influence the average. Figure 6 shows the individuals across time. The individual trajectories reveal a striking uniformity: twelve out of thirteen speakers show an increase in F2 across the time points. While there is some variability in the degree of shifting (the smallest is $17 \mathrm{~Hz}$; largest 226 ; average 98 ), the speakers are reasonably parallel. 
In addition to parallel shifts, the speakers also converge where the range between averages decreases from $334 \mathrm{~Hz}$ in 2012 to $278 \mathrm{~Hz}$ in 2016 . Overall, nearly all speakers shift in the predicted direction; they shift in step, and appear to be converging on a new norm.

To summarise, GOOSE-fronting behaved largely as expected: there was a visible and significant adolescent peak in apparent time where the young cohort showed higher F2 levels than the children in 2012. Adding the real time data to this perspective showed the predicted uptick where the children increased their F2 levels over time and moved towards the frontline of the community change. Analysis of the individual trajectories showed the same pattern in twelve out of thirteen speakers who also demonstrated a convergence in rates of use across time. Statistical analysis of the 2016 data confirmed that, in line with the majority of studies, this variable was not significantly conditioned by 'stylistic context' $(p=.24)$.

GOOSE-fronting, a variable that lacks any strong social profile, demonstrates a linear line of incrementation. For this variable, the children are set one task: continue the change in the direction of the community. But how will these patterns of incrementation compare to the variables that also require a level of social awareness? The following sections present the findings from the two stigmatised forms, starting with TH-fronting.

\section{TH-fronting}

TH-fronting refers to the variable replacement of the voiceless interdental fricative with the voiceless labiodental fricative (Wells 1982:328), as in (1) below.

(1) My brother went to, like, Thorpe [fop] Park now they've changed it and we went to a cathedral [kəfidrəł]. (Gerrard, 14)

TH-fronting has shown extremely rapid spread to a number of dialects of British English: Southern British English (Tollfree 1999; Altendorf \& Watt 2008; Schleef \& Ramsammy 2013), as well as to northern dialects and in Scottish English (Llamas 1998; Docherty \& Foulkes 1999; Mathisen 1999; Milroy 2003; Flynn 2012). The feature is strongly associated with London, particularly with the working-class, east-end variety Cockney (Kerswill 2003:231). The spread of TH-fronting throughout the UK has been attributed to a process of diffusion. Kerswill (2003:231) labels it a 'torchbearer' on account of the speed and reach of its spread. Apparent time studies have shown that once arrived, the feature shows striking increase across the generations (Llamas 1998:106; Docherty \& Foulkes 1999:51; Watt \& Milroy 1999:31; Stuart-Smith \& Timmins 2006:174). Despite its success, TH-fronting is highly stigmatised to the extent that parents will openly correct it in the speech of their children (Tollfree 1999:172; Altendorf \& Watt 2008:192). Importantly, for the purpose of the current investigation, studies have also shown that speakers are sensitive to context and use lower rates of the fronted variant in more formal situations (Neilsen 2010:33; Flynn 2012:326). 
Before analysing the potential for this social profile to impact on the real time patterns of incrementation, the apparent time trends will indicate the nature of the community age vector.

\section{TH-fronting: Apparent time}

The final model (Appendix C) showed that rates of TH-fronting rose significantly over time and that men favour the change. Model estimates increase across each of the age cohorts with the exception of the children who, as predicted, show lower estimates than the young speakers. Research indicates TH-fronting is strongly conditioned by syllable position (Stuart-Smith \& Timmins 2006; Clark \& Trousdale 2009) where syllable onsets (thing, nothing, etc.) are less susceptible to fronting than codas (e.g. bath, maths, southwest, wealthy, etc.). In order to control for this effect in the model, following a finer grained categorisation, position was collapsed into two levels: onset and coda. In line with previous work, onset environments show significantly lower rates of fronting. Neither gender nor position showed a significant interaction with age indicating that these factors show consistent patterning across the generations. Figure 7 illustrates the findings for age (left panel) and age by gender (right panel).

Like many communities adopting this change, the feature shows an extremely rapid increase across apparent time in Hastings. Older speakers use the form at a rate of $15 \%$ while younger speakers show an average rate above $75 \%$. This rapid increase is confirmed by the EMMs: there is a significant difference between the adult cohorts (older - middle-aged $p=.02$; middle-aged - young $p=.0009$ ). While there is a visible adolescent peak, the children show very high rates compared
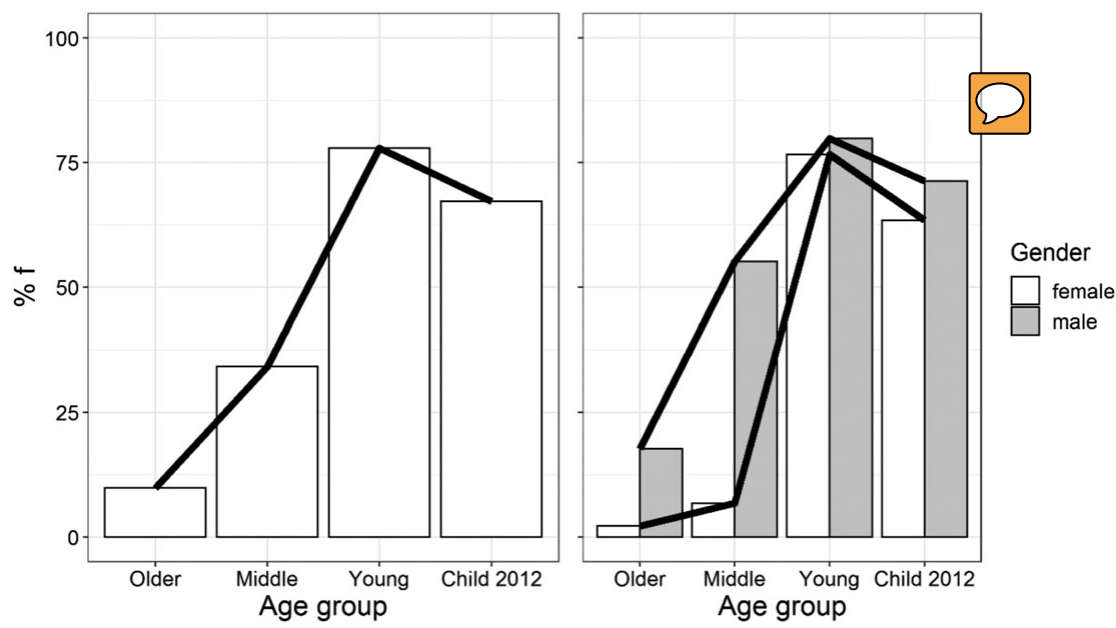

FIGURE 7. TH-fronting: aggregate apparent time and gender across apparent time. 

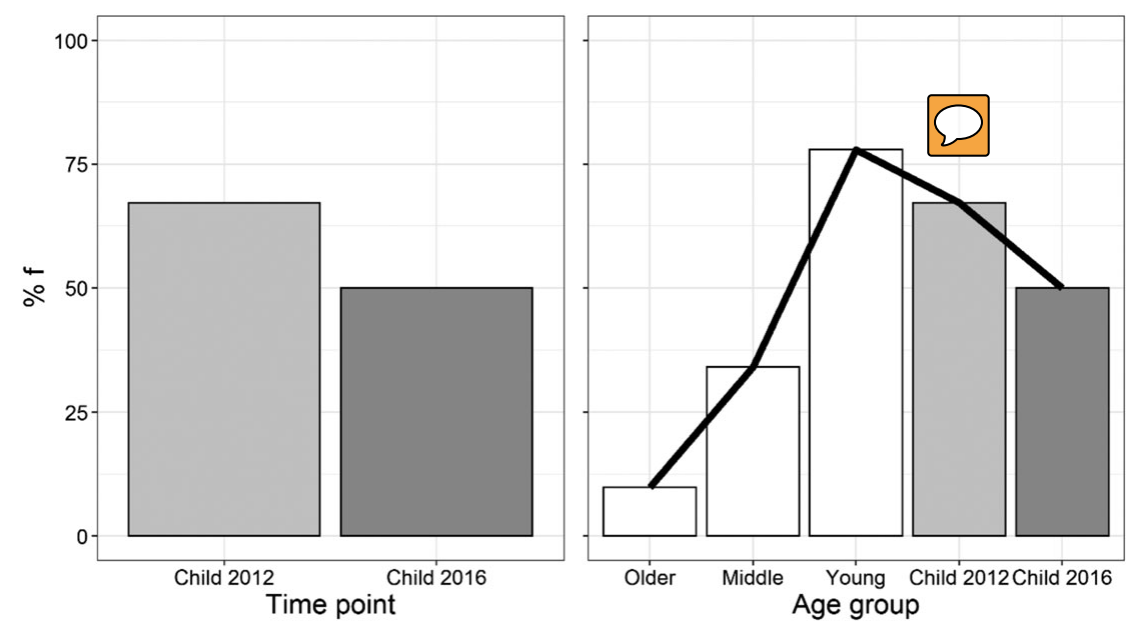

FIGURE 8. TH-fronting: real time and apparent time.

to the adult population and most closely resemble the rates of the young speakers; the difference between the young adults and the children is not significant $(p=.86)$.

From the apparent time results, it would appear that $\mathrm{TH}$-fronting provides a marked age vector. This should enable the speakers to gauge the direction of the change and increment in real time.

\section{TH-fronting: Real time}

The final real time model (Appendix D) selected time point and syllabic position as significant. In contrast to the apparent time model, gender was not significant, which may indicate a continued weakening of this constraint in the community. ${ }^{1}$ Figure 8 illustrates real time findings (left panel), contextualised within the apparent time pattern (right panel). In contrast to the patterns found for GOOSE-fronting, between 2012 and 2016 the speakers actually decrease their rates of the change in progress. Instead of incrementing the change in the direction that has been set by the age vector in the wider community, the young speakers appear to be reversing the change. However, while this pattern is visible at a group level, it is necessary to see if this withdrawal is the case for all of the speakers, or only some. It may be that a minority of conservative speakers substantially reduce their rates. The individual trajectories are shown in Figure 9. In contrast to the individual behaviour for GOOSE-fronting that was characterised by uniformity and convergence, the individuals show no uniform pattern across TH-fronting and a marked divergence over time. Of the thirteen individuals, seven show a decrease in rates, two remain stable, and four increase. The overall pattern suggests a lack of consensus. It may 


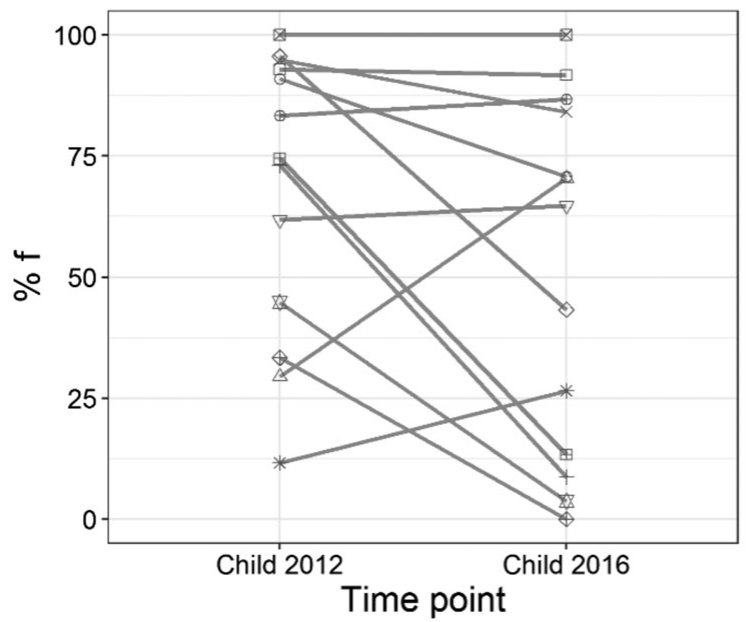

Speaker

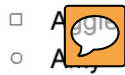

$\triangle$ Bobby

+ Brian

$\times$ Gerrard

$\diamond$ Issy

$\nabla$ Jerry

$\otimes$ Jones

* Kamaria

$\oplus$ Lauren

$\oplus$ Louise

\& Nicky

$\boxplus$ Rachel

FIGURE 9. TH-fronting: individual trajectories across real time.

be that while the age vector was stark, the degree of socially motivated variability obscured the generational pattern. This may have created a scenario where the speakers struggled to separate the style-based variance from the age patterning. If the young speakers have failed to extract the social evaluation, this may have impacted on their ability to extract the age vector. One way to explore this is to examine whether the speakers showed significant style shifting.

\section{TH-fronting: Style in 2016}

A final model was run on the TH-fronting data to test the effect of style within the second set of real time interviews (Appendix E). The model shows that context significantly conditioned the variation. As illustrated in Figure 10, as speech becomes less monitored, rates of TH-fronting increase. Analysis of EMMs indicates that conversation $(p=.002)$ and interview $(p=.02)$ contexts show significantly higher rates than reading. Conversation and interview contexts are visibly but not significantly different.

The analysis of stylistic context, suggests that the young speakers have acquired the broader, social evaluation of the feature and replicated this constraint in their own speech. However, while they may have mastered the style dimension, they have not successfully internalised the age vector. It is not clear why the speakers have not positively incremented the change. A comparison of these findings with those from T-glottaling may shed light on this issue. 


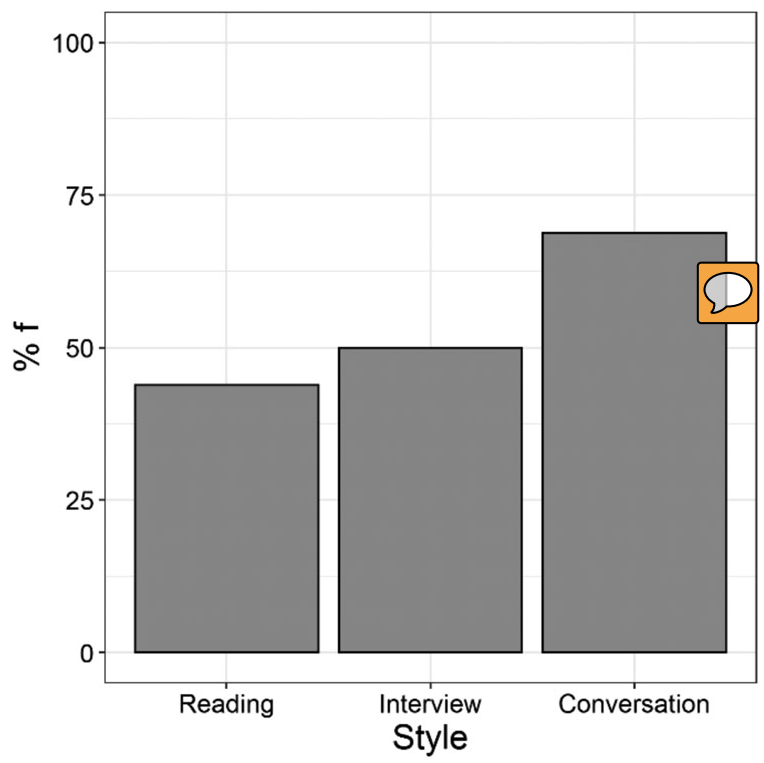

FIGURE 10. TH-fronting: style in 2016 data.

\section{T-glottaling}

T-glottaling, or glottal replacement, occurs when a noninitial underlying / $t /$ is realised as an auditorily distinct 'glottal stop', which masks or entirely replaces the oral stop, as in (2) below (see also Wells 1982:65, 261; Schleef 2013:201).

(2) I dunno when I start [sta?], but [b $\Lambda$ ?] it's pretty [prI?i] good, (Amy, 13)

While it may be more commonly associated with southern varieties of British English (Tollfree 1999), T-glottaling is found throughout the UK: in northern dialects (Docherty \& Foulkes 1999; Baronowski \& Turton 2015), in Welsh English (Mees \& Collins 1999), and in Scottish English (Andrésen 1968; Stuart-Smith 1999). Its use throughout the UK has led it to become a stereotype of British speech. Despite its prevalence, T-glottaling, particularly in intersonorant contexts (e.g. water, pretty), is still regarded as a nonstandard feature that Milroy, Milroy, Hartley, \& Walshaw (1994:4) characterise as one of the 'most heavily stigmatized features of British English'. Sociolinguistic research supports this description where speakers exhibit a sensitivity to context and use lower rates in more formal speech (Trudgill 1999:132; Stuart-Smith 1999:191), and caregivers will often correct for it in the speech of their children (Foulkes et al. 2005:190). However, while it has long been stigmatised, there is evidence to suggest that its reign as the UK's treasured linguistic outlaw is coming to an end. Fabricius 
(2002) finds it is increasing in young RP speakers, and Stuart-Smith (1999:199) also finds a weakening of the stylistic constraint within the younger speakers in her study of Scottish English. Even with its stigma fading, in many ways, T-glottaling shares the linguistic and social profile of TH-fronting. It is a binary, nonstandard, consonantal feature. Therefore, we may expect similar patterns across real time where young speakers exhibit incomplete mastery of the variation associated with this form.

\section{T-glottaling: Apparent time}

The final apparent time model (Appendix F) selected age and gender as fixed social factors. Previous research demonstrates that rates of T-glottaling are highly constrained by linguistic environment (Docherty \& Foulkes 1999; Drummond 2011; Flynn 2012). Following similar analyses (Smith \& Holmes-Elliott 2017), environment was controlled for in the model through 'linguistic context': a four-way split that captures the intersection of syllabic and phonological environments. ${ }^{2}$ Figure 11 illustrates the findings across age and gender: a steady increase in the innovative form across the generations of adult speakers with the children exhibiting lower rates than the young adults. Men show a significantly higher rate of T-glottaling than women consistently across the age groups.

In contrast to the extremely rapid acceleration shown by TH-fronting, T-glottaling shows a steadier incline with the most substantial rise occurring between the older and middle generations. This is reflected by the post hoc EMM comparisons that revealed older speaker rates were significantly different to the middle-aged $(p=.03)$ and younger speakers $(p<.0001)$, but middle-aged speakers were not significantly lower than the young adults $(p=.07)$. However, in contrast to TH-fronting, the children have significantly $(p=.03)$ lower levels than the youngest apparent time speakers. Unlike TH-fronting, the high rates of use in the older participants (average 53\% compared to 15\%) indicate that this form has been an established feature of the dialect for a number of generations. Moreover, there is a significant adolescent peak for this feature where the children in 2012 show equivalent rates to the middle-aged speakers.

\section{T-glottaling: Real time}

The final real time model (Appendix G) selected linguistic context and time point as significant; gender was not selected. Figure 12, illustrates the speakers' significant increase in T-glottaling across the time points. The right-hand panel in Figure 12 indicates that the real time speakers have moved from exhibiting levels similar to the middle-aged speakers and now more closely resemble the young cohort. Although this real time increase is predicted by the incrementation model of change, given its similarity to TH-fronting, it is surprising that T-glottaling does not exhibit the same patterning in real time. 

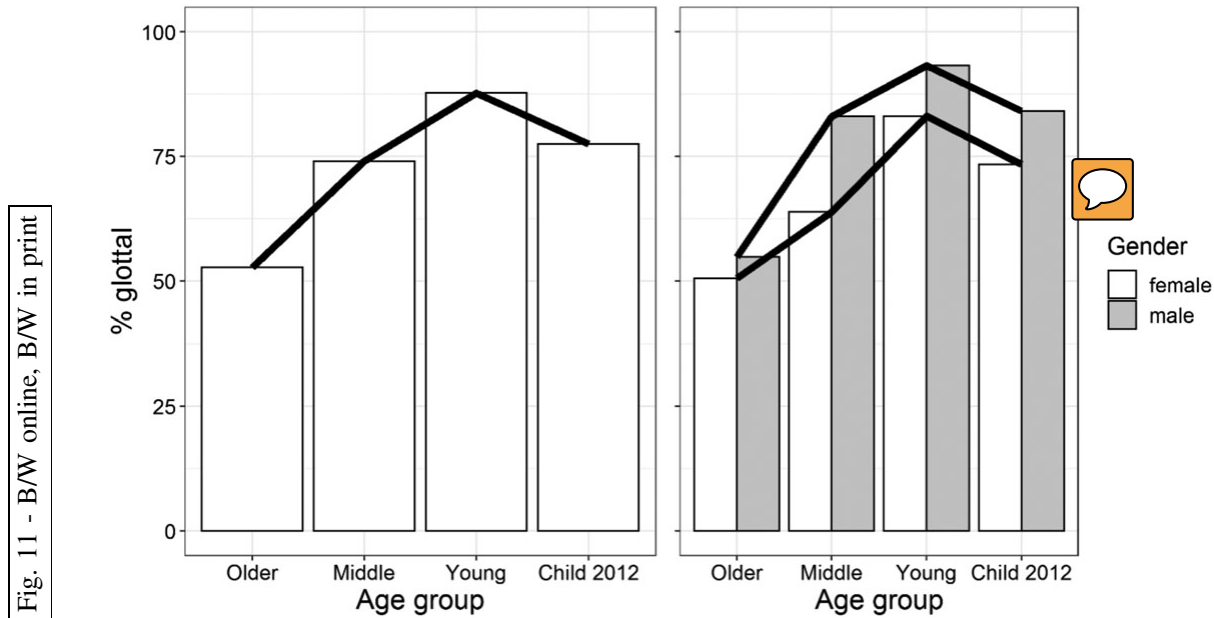

FIGURE 11. T-glottaling: aggregate apparent time and gender across apparent time.
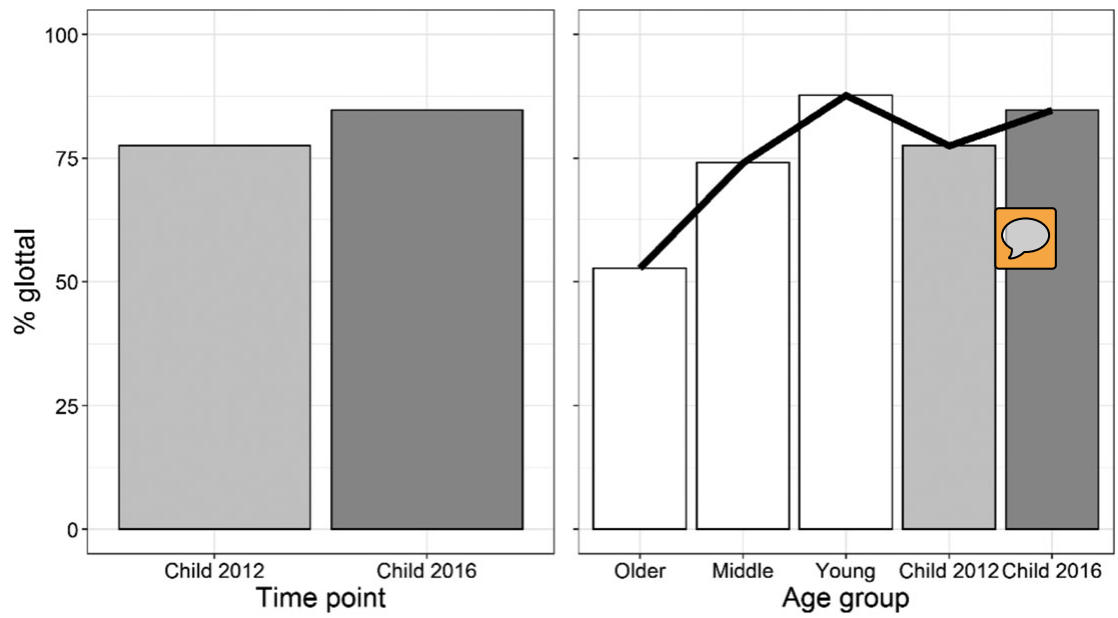

FIGURE 12. T-glottaling: real time and apparent time.

While the aggregate real time data for T-glottaling is at odds with the TH-fronting results, how do the individuals compare? Figure 13 shows the individual trajectories across real time. Compared to the irregular patterning shown across the individuals for TH-fronting, the speaker trajectories look remarkably uniform for T-glottaling: eight out of the thirteen speakers increase their rates with visible parallelism between the trajectories. What is more, despite the observation that 


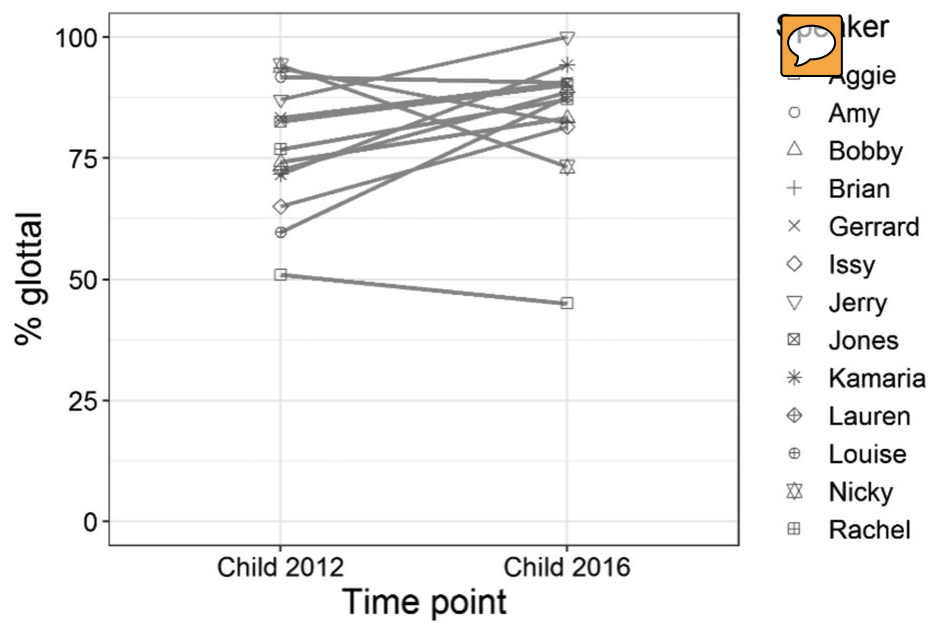

FIGURE 13. T-glottaling: individual trajectories across real time.

speakers may shift in different directions across real time, overall the speakers show a marked convergence with seven of the speakers averaging around $85 \%$ in 2016.

In comparison to the previous features, so far T-glottaling has more closely resembled GOOSE-fronting: increased use of the innovative form in real time and a high level of interspeaker uniformity. This is unexpected given that speakers failed to increment the change in the community direction for the other stigmatised form and also showed a lack of convergence. One possible explanation is that T-glottaling is no longer subject to stigma. This would mean that the young speakers are able to increment in real time because the age vector is more apparent as it is unobscured by variance brought about through style shifting. Analysis of style in 2016 confirms whether this is the case.

\section{T-glottaling: Style in 2016}

A final model was run to test the effect of context within the 2016 data (Appendix H). Results demonstrate a significant effect of style: speakers show lower rates of T-glottaling when reading compared to the baseline conversation context. Model estimates indicate that speakers use slightly higher rates in interview contexts compared to conversation; however, this difference is not statistically significant. The style effect is clear from Figure 14: although the speakers make a big concession to reading, they make little adjustment across the two spontaneous contexts. While the distributional patterns look slightly different to TH-fronting, the statistical analysis demonstrates the same finding: a significant difference in reading compared to spontaneous contexts. This indicates that in line with their general descriptions, the two features have similar social profiles within this specific 


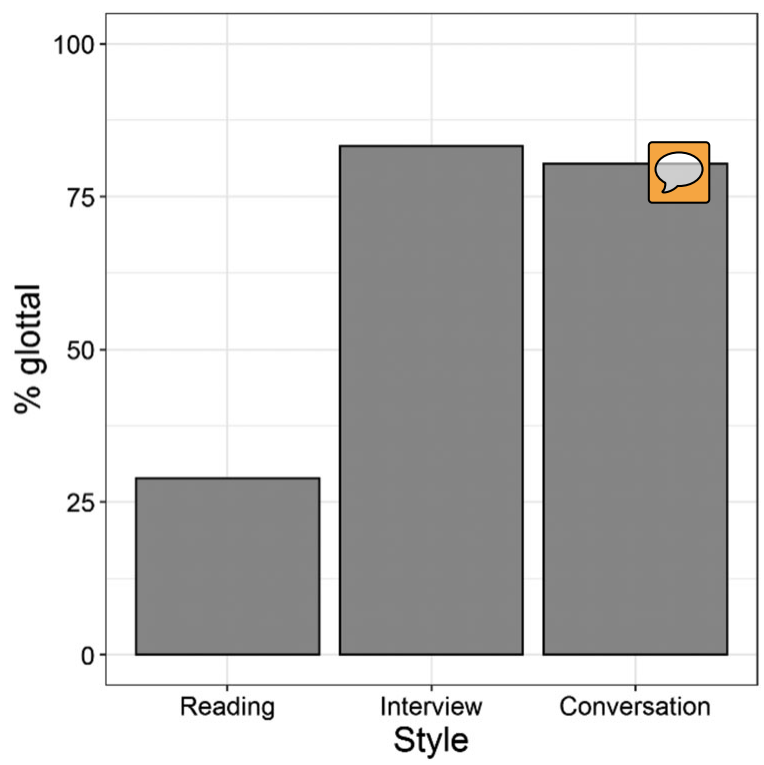

FIGURE 14. T-glottaling: style in 2016 data.

dialect. However, they exhibit very different patterns across real time. The possible reasons for this difference are discussed below.

\section{I S C U S S I O N}

It is now possible assess the relationship between the community-wide generational patterns and the young speakers' real time shifts. To ease comparison across the features, Table 4 provides an overview of the main findings. The first feature, GOOSE-fronting, behaved as predicted: steady monotonic change in apparent time complete with adolescent peak. Then in real time, there is an incremental shift towards the leading edge of change across the panel and in twelve out of the thirteen individual speakers. Increased conformity to the community-wide patterns is also evident in changes to the linguistic conditioning across real time. In 2012, the constraint in the child data was statistically and visibly at odds with the trend in the wider community. In 2016, while the irregular pattern remained, the distribution of the data echoed the apparent time trend where the effect was weakening. In sum, the speakers converge on a fronter average GOOSE target and increment the overall change. They also continue the generational trend across the linguistic conditioning by showing further weakening in the phonological constraint. Across both the aggregate pattern and the underlying variable grammar, the young speakers adhere to the diachronic norm set by the apparent time pattern of the community. The 
TABLE 4. Overview of main findings from apparent and real time across three features.

\begin{tabular}{lclcccc}
\hline \hline Feature & $\begin{array}{c}\text { Socially } \\
\text { marked }\end{array}$ & $\begin{array}{l}\text { Apparent time } \\
\text { trend }\end{array}$ & $\begin{array}{c}\text { Adolescent } \\
\text { peak }\end{array}$ & $\begin{array}{c}\text { Real time } \\
\text { trend }\end{array}$ & $\begin{array}{c}\text { Individual } \\
\text { patterning }\end{array}$ & $\begin{array}{c}\text { Style } \\
\text { shifting }\end{array}$ \\
\hline GOOSE-FRONTING & no & steady increase & yes & increase & $\begin{array}{c}\text { convergent: } \\
\text { uniform } \\
\text { increase }\end{array}$ & no \\
TH-FRONTING & yes & rapid increase & yes (n.s.) & decrease & $\begin{array}{c}\text { divergent: } \\
\text { majority } \\
\text { decrease }\end{array}$ & yes \\
T-GLOTTALING & yes & steady increase & yes & increase & $\begin{array}{c}\text { convergent: } \\
\text { majority } \\
\text { increase }\end{array}$ & yes \\
\hline \hline
\end{tabular}

aggregate finding echoes those from a previous study of young speakers from Milton Keynes. Cited in Kerswill (2010:241-42), Kassab (2008) tracked the real time developments of two speakers across a two-year period and reports fronter GOOSE measures from the second recordings. Taken together with the results from the present study, these findings provide strong, direct evidence for the incrementation model of sound change.

The aggregate and the individual patterns for GOOSE-fronting indicate that the young speakers have no issues deciphering the pattern and ratcheting the change to the next stage of development. The straightforward incrementation is predicted as the community pattern provides a clear age vector unaffected by style shifting. In contrast, TH-fronting and T-glottaling present potentially harder vectors to interpret. However, this only appeared to impact on the real time trajectories of TH-fronting; T-glottaling more closely resembled the patterning of GOOSEfronting. As demonstrated by the results, and summarised in Table 4, the socially marked variables showed similarities and differences. The apparent time results showed that both features were in a process of ongoing change, complete with adolescent peaks. However, while TH-fronting showed an extremely rapid increase across the generations, T-glottaling showed a steadier incline. Moreover, although both changes exhibited visible adolescent peaks, only T-glottaling showed a statistically significant one. The differences in real time between the two forms were even more notable. The first analysed form, TH-fronting, showed a significant decrease and interspeaker divergence. In contrast, the overall rates of T-glottaling increased and speakers showed a high level of convergence in 2016. In short, young speakers failed to increment TH-fronting at both a group and an individual level yet succeeded for T-glottaling. But why did TH-fronting, a change that appears to present a clearer generational pattern than T-glottaling, create a greater challenge for the young speakers incrementing the change?

One possible explanation for the difference in real time was that T-glottaling had lost its stigma while TH-fronting had not. However, analysis of style in the 2016 

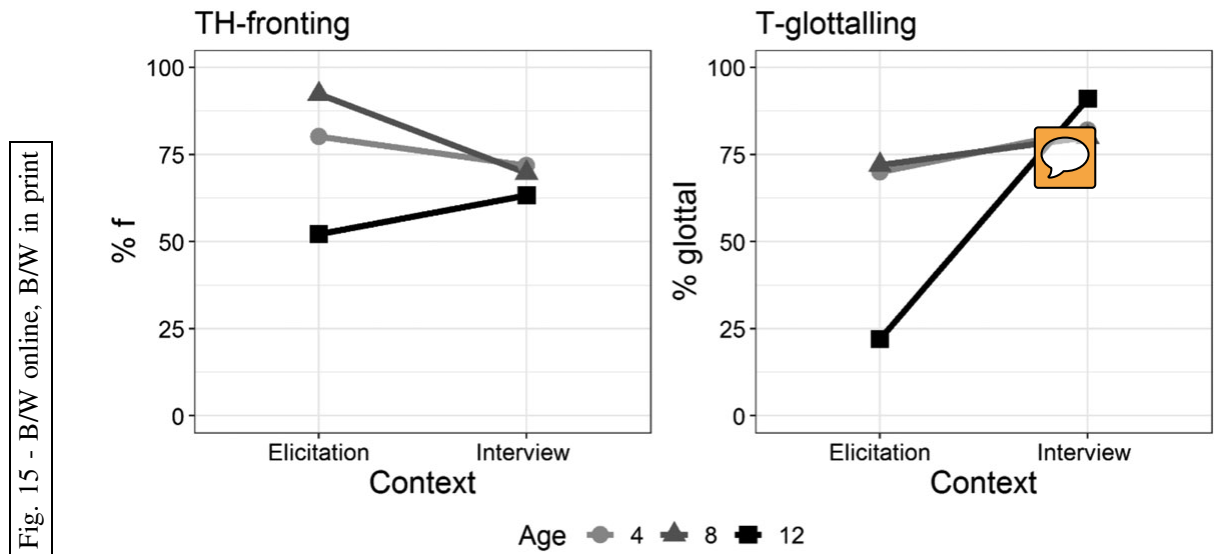

FIGURE 15. Style shifting by age across TH-fronting and T-glottaling in Milton Keynes (based on Kerswill \& Williams 2000:98).

data showed significant shifting across both forms. This suggests that the social evaluation of both features was still evident to the extent that the young speakers had internalised and could replicate the style-shifting behaviour of the wider community. It would therefore appear that the young speakers found something in the OVERALL community variance of TH-fronting harder to interpret compared to T-glottaling. Corroborating evidence in support of this interpretation comes from Kerswill \& Williams (2000) who showed that the specific variable had a bearing on the age at which style emerged in young speakers in Milton Keynes. In their study, they analysed a range of features in the speech of children aged four, eight, and twelve - all younger than the speakers analysed in the current study. Kerswill \& Williams (2000) found that the age of the child affected both the ability to shift in the right direction, as well as the magnitude of their shifting. The results are replicated in Figure 15.

For TH-fronting only the older children showed style shifting in the 'correct' direction where they use lower rates in the elicitation task compared to the interview. In contrast, for T-glottaling, all children showed style shifting but the shift was more pronounced in the older speakers. This would suggest that for TH-fronting, only the older speakers had acquired the evaluation, whereas even the four-year olds had developed at least some awareness of the stigma attached to T-glottaling. Based on Kerswill \& Williams' (2000) data, as well as the analysis of the real time data from Hastings, it would appear that interpreting the community variance of TH-fronting poses a greater challenge. The reason for this, as suggested by Kerswill \& Williams (2000:105), is that alongside developmental factors, the emergence of style shifting is constrained by the specific status and patterning of the form within the community. 

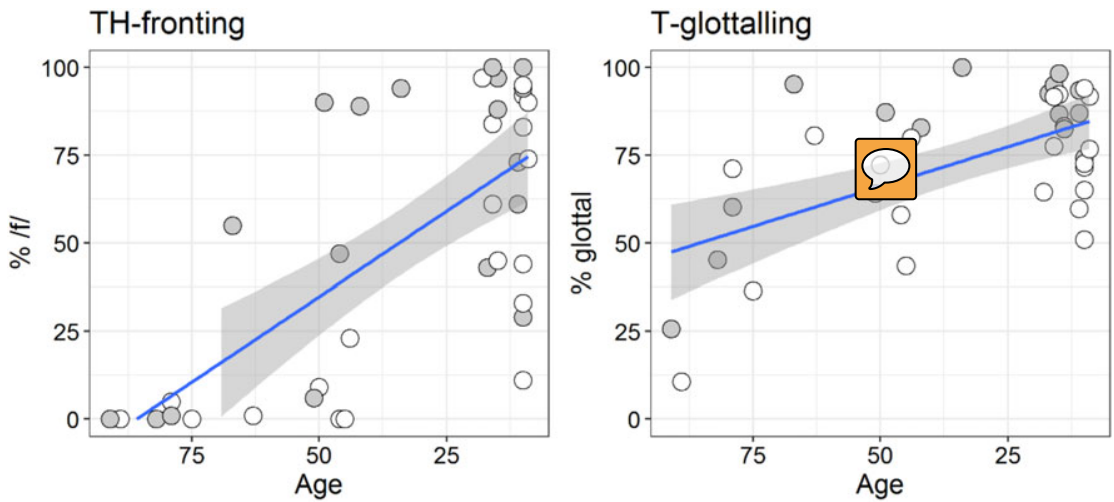

Gender $\bigcirc$ female $\bigcirc$ male

FIGURE 16. Individual rates of TH-fronting and T-glottaling by age in Hastings.

Specifically for TH-fronting within the Hastings data, while the speakers have mastered the style norm, they have yet to master the associated age norm. As a result they fail to increment the change in the correct direction. A possible reason for the observed difference is that interspeaker variance within the community impacts on a learner's ability to extract the vector. In other words, if interspeaker variance is too high, then generational patterns can become obscured. Indeed, rates of TH-fronting and T-glottaling as they pattern for the individuals across apparent time in Hastings, shown in Figure 16, go some way to explaining why the diachronic community norm for TH-fronting may be harder to gauge than that of T-glottaling. There are revealing differences between the distributions of individual rates across the two variables. Most striking is the difference in range both across time and also between individuals. As demonstrated previously, and shown above by the much steeper trend line, TH-fronting exhibits a much more rapid increase across the generations compared to T-glottaling. However, as well as a wider range across time, the interspeaker variability across the adults is much greater for TH-fronting. This is particularly marked within the middle-aged speakers. Here the individuals span almost the entire range with some individuals showing near categorical rates of the standard, and others using near categorical rates of the nonstandard. For T-glottaling, in contrast, the adult speakers cluster more closely to the mean. The difference is reflected by the children as they were recorded in 2012, where they too exhibit a much larger interspeaker range for $\mathrm{TH}$-fronting compared to T-glottaling.

The differences observed across the two variables speak to the broader question of exactly where, and how, the young speakers are extracting social information about the features. According to the momentum-based account, the individual 
distributions in the Hastings data would predict the difference observed across TH-fronting compared to T-glottaling.

[I]solated and randomly distributed innovations are actively repressed; innovations that accidentally cluster in a pattern inversely correlated with age are not only adopted, but also actively incremented by the learner. (Bermúdez-Otero 2020)

The data presented here support this prediction where the community patterns have clear implications for the ease at which the children can acquire the community norms. The more variable a change, the later we can expect sociolinguistic competence to be reached (cf. Kerswill \& Williams 2000), and in turn, incrementation to take place. When the individuals within a community show a wide range of variation, it becomes harder for young speakers to determine the generational pattern and diagnose the vector. If learners cannot scale their rates against clear community norms, it delays their ability to increment language change. Evidently, learners must calibrate before they can innovate.

\section{O N C L U S I O N}

Contrasting a set of variables across real and apparent time has enabled an investigation into the relationship between variable patterns within the community and the ease at which children can interpret variation and increment change. Results indicate that children are relatively adept at acquiring the social evaluation of forms and replicating this pattern in their own speech. However, when interspeaker community variance is extreme, young speakers struggle to interpret the momentum in apparent time and fail to increment the change in the correct direction. While this study represents a step forward in our understanding of the broader connection between community patterns and incrementation, a number of questions remain. For instance, the combination of larger real and apparent time data corpora will enable a much more precise and quantitative modelling of the relationship between interspeaker variability and young speakers' real time incrementation of language change. Further, work which focusses on children's ability to perceive and interpret age-based variance stands to shed light on the cognitive mechanisms underpinning this process.

Perhaps more crucially, while the present work may shed light on How children increment change, understanding WHY they do remains a challenge. Eckert (2011:90-91) suggests that preadolescent patterns of variation and change are related to the power dynamics of the social order. The pressure to be, and be seen as 'legitimately adolescent', amplifies the potential for variance and innovation in all aspects of behaviour, including speech. Children seek to keep up with the older trendsetters and avoid being 'left in the developmental dust' (Eckert 2011:88). This context possibly creates a linguistic hothouse for language change: increased linguistic variance, strong peer group influence, and intense social pressure to 'grow up'. Clearly, an interdisciplinary approach that combines 
variationist, cognitive, and sociological perspectives offers a productive way into the seeming 'mystery' of what Sankoff (2018) terms 'early life span change'.

\section{N O T E S}

*This research was supported by the British Academy (grant no. SG-162287). Many thanks to James Turner, the project research assistant. I am grateful to the editors of Language in Society and two anonymous reviewers who helped to improve this manuscript. I would also like to thank Jennifer Smith, Erez Levon, and the audience at UK LVC 2019 for their feedback on an earlier version of the work. Any remaining shortcomings are my own. Special thanks to my speakers from Hastings who made this research possible. I would like to acknowledge that this research was conducted at the Department of Modern Languages and Linguistics, University of Southampton. However, my current affiliation is Queen Mary University of London.

${ }^{1}$ The emergence of gendered speech production is beyond the scope of this analysis but is the focus of previous and forthcoming work by the author (Holmes-Elliott \& Turner 2019).

${ }^{2}$ The categories for linguistic context were as follows: ambi-syllabic with following syllabic consonant: bottle, bitten, pattern; ambi-syllabic with following vowel: pretty, computer, thirty; word final with following vowel: put up, that is; word final with following pause: Great!, You're right.

\section{R E F E R E N C E S}

Aitchison, Jean (1981). Language change: Progress or decay? London: Fontana.

Altendorf, Ulrike, \& Dominic Watt (2008). The dialects in the south of England: Phonology. In Bernd Kortmann \& Clive Upton (eds.), Varieties of English, vol. 1: The British Isles, 194-222. Berlin: Mouton de Gruyter.

Andrésen, Bjørn Stålhane (1968). Pre-glottalization in English standard pronunciation. Oslo: Norwegian Universities Press.

Baranowski, Maciej (2017). Class matters: The sociolinguistics of goose and goat in Manchester English. Language Variation and Change 29(3):301-39.

_ \& Danielle Turton (2015). Manchester English. In Raymond Hickey (ed.), Researching Northern Englishes, 293-316. Amsterdam: John Benjamins.

Bates, Douglas; Martin Maechler; Ben Bolker; \& Steve Walker (2015). Fitting linear mixed-effects models using lme4. Journal of Statistical Software 67(1):1-48.

Bermúdez-Otero, Ricardo (2020). The initiation and incrementation of sound change: Community-oriented momentum-sensitive learning. In James Kirby, Lauren Hall-Lew, \& Patrick Honeybone (eds.), Individuals, communities, and sound change. Special collection in Glossa, to appear.

Boudahmane, Karim; Mathieu Manta; Fabien Antoine; Sylvain Galliano; \& Claude Barras (2008). Transcriber [Software]. Online: http://trans.sourceforge.net.

Catford, John. C. (1988). A practical introduction to phonetics. Oxford: Clarendon Press.

Cheshire, Jenny L.; Paul Kerswill; Sue Fox; \& Eivind Torgersen (2011). Contact the feature pool and the speech community: The emergence of Multicultural London English. Journal of Sociolinguistics 15(2):151-96.

Chevrot, Jean-Pierre; Laurence Beaud; \& Renata Varga (2000). Developmental data on a French sociolinguistic variable: Post-consonantal word-final /R/. Language Variation and Change 12(3):295-319.

Clark, Lynn, \& Graeme Trousdale (2009). Exploring the role of token frequency in phonological change: Evidence from TH-fronting in east-central Scotland. English Language and Linguistics 13(1):33-55.

Clarke, Sandra; Elms Ford; \& Youssef Amani (1995). The third dialect of English: Some Canadian evidence. Language Variation and Change 7(2):209-28. 


\section{CALIBRATE TO INNOVATE}

Cox, Felicity (1999). Vowel change in Australian English. Phonetica 56(1):1-27.

Díaz-Campos, Manuel (2005). The emergence of adult-like command of sociolinguistic variables: A study of consonant weakening in Spanish-speaking children. In David Eddington (ed.), Studies in the acquisition of the Hispanic languages: Papers from the 6th Conference on the Acquisition of Spanish and Portuguese as First and Second Languages, 56-65. Somerville, MA: Cascadilla.

(2011). Becoming a member of the speech community: Learning socio-phonetic variation in child language. In Manuel Díaz-Campos (ed.), The handbook of Hispanic sociolinguistics, 26383. Malden, MA: Wiley-Blackwell.

Docherty, Gerard. J., \& Paul Foulkes (1999). Instrumental phonetics and phonological variation: Case studies from Newcastle upon Tyne and Derby. In Foulkes \& Docherty, 47-71.

Drummond, Rob (2011). Glottal variation in /t/ in non-native English speech: Patterns of acquisition. English World-Wide 32(3):280-308.

Easton, Anita, \& Laurie Bauer (2000). An acoustic study of the vowels of New Zealand English. Australian Journal of Linguistics 20:93-117.

Eckert, Penelope (2000). Linguistic variation as social practice. Oxford: Blackwell.

(2011). Language and power in the preadolescent heterosexual market. American Speech 86:85-97.

Ervin-Tripp, Susan (1972). Sociolinguistic rules: Alteration and co-occurrence. In John Gumperz \& Dell Hymes (eds.), Directions in sociolinguistics, 213-50. Cambridge: Basil Blackwell.

Fabricius, Anne (2002). Ongoing change in modern RP: Evidence for the disappearing stigma of t-glottalling. English World-Wide 23(1):115-36.

Flynn, Nicholas (2012). A sociophonetic study of Nottingham speakers. York: University of York PhD dissertation.

Fought, Carmen (1999). A majority sound change in a minority community: /u/-fronting in Chicano English. Journal of Sociolinguistics 3(1):5-23.

Foulkes, Paul, \& Gerard Docherty (eds.) (1999). Urban voices: Accent studies in the British Isles. London: Arnold.

$\longrightarrow ;-; \&$ Dominic Watt (2005). Phonological variation in child directed speech. Language 81:177-206.

Fridland, Valerie (2008). Patterns of /uw/, / /, and /ow/ fronting in Reno, Nevada. American Speech 83(4):432-54.

Haddican, Bill; Paul Foulkes; Vincent Hughes; \& Hazel Richards (2013). Interaction of social and linguistic constraints on two vowel changes in northern England. Language Variation and Change 25(3):371-403.

Hall-Lew, Lauren (2011). The completion of a sound change in California English. In Wai Sum Lee \& Eric Zee (eds.), Proceedings of the 17th International Congress of Phonetic Sciences, 17-21 August 2011, Hong Kong. Hong Kong: City University of Hong Kong.

Harrington, Jonathan; Felicitas Kleber; \& Ulrich Reubold (2008). Compensation for coarticulation, $/ \mathrm{u} /$-fronting, and sound change in Standard Southern British: An acoustic and perceptual study. Journal of the Acoustical Society of America 123(5):2825-35.

Holmes-Elliott, Sophie (2016). Ladies first? Adolescent peaks in a male-led change: TH-fronting in southeast England. University of Pennsylvania Working Papers in Linguistics 22(2), article 10. Online: https://repository.upenn.edu/cgi/viewcontent.cgi?article=1930\&context=pwpl.

— \& James Turner (2019). The emergence of gendered production between childhood and adolescence: A real time analysis of /s/ in Southern British English. In Sasha Calhoun, Paola Escudero, Marija Tabain, \& Paul Warren (eds.), Proceedings of the 19th International Congress of Phonetic Sciences, Melbourne, Australia 2019, 2670-74. Canberra: Australasian Speech Science and Technology Association.

Kassab, Werdan (2008). A linguistic change in a newly-formed town. Lancaster: Lancaster University MA dissertation. 


\section{SOPHIE HOLMES-ELLIOTT}

Kerswill, Paul (2003). Dialect levelling and geographical diffusion in British English. In David Britain \& Jenny Cheshire (eds.), Social dialectology, In honour of Peter Trudgill, 223-44. Amsterdam: John Benjamins.

(2010). Sociolinguistic approaches to language change: Phonology. In Ruth Wodak, Barbara Johnstone, \& Paul Kerswill (eds.), The SAGE handbook of sociolinguistics, 219-35. London: SAGE.

— \& Anne Williams (2000). Creating a New Town koine: Children and language change in Milton Keynes. Language in Society 29(1):65-115.

Kirkham, Sam, \& Emma Moore (2013). Adolescence. In Jack Chambers, Natalie Schilling-Estes, \& Peter Trudgill (eds.), The handbook of language variation and change, 277-96. Oxford: Blackwell.

Kohn, Mary, \& Charlie Farrington (2012). Evaluating acoustic speaker normalization algorithms: Evidence from longitudinal child data. The Journal of the Acoustical Society of America 131(3):2237-48.

Kuznetsova, Alexandra; Per Bruun Brockhoff; \& Rune Haubo Bojesen Christensen (2016). LmerTest: Tests for random and fixed effects for linear mixed effect models (lmer objects of lme4 package). Online: https://cran.r-project.org/web/packages/lmerTest.

Labov, William (1984). Field methods of the project on linguistic change and variation. In John Baugh \& Joel Sherzer (eds.), Language in use: Readings in sociolinguistics, 28-53. Englewood Cliffs, NJ: Prentice-Hall. (1994). Principles of linguistic change, vol. 1: Internal factors. Oxford: Blackwell. (2001). Principles of linguistic change, vol. 2: External factors. Oxford: Blackwell. (2007). Transmission and diffusion. Language 83:344-87.

(2012). What is to be learned: The community as the focus of social cognition. Review of Cognitive Linguistics 10:265-93.

Lenth, Russell (2017). Using lsmeans. R Foundation for Statistical Computing, Vienna, Austria. Online: https://cran.r-project.org/web/packages/lsmeans/vignettes/using-lsmeans.pdf.

Llamas, Carmen (1998). Language variation and innovation in Middlesbrough. Leeds Working Papers in Linguistics and Phonetics 6:9-115.

Lobanov, Boris M. (1971). Classification of Russian vowels spoken by different listeners. Journal of the Acoustical Society of America 49:606-608.

Mathisen, Anne G. (1999). Sandwell, West Midlands: Ambiguous perspectives on gender patterns and models of change. In Foulkes \& Docherty, 107-23.

Mees, Inger M., \& Beverley Collins (1999). Cardiff: A real-time study of glottalisation. In Foulkes \& Docherty, 185-202.

Mesthrie, Rajend (2010). Sociophonetics and social change: Deracialisation of the GOOSE vowel in South African English. Journal of Sociolinguistics 14(1):3-33.

Milroy, James (2003). When is a sound change? On the role of external factors in language change. In David Britain \& Jenny Cheshire (eds.), Social dialectology: In honour of Peter Trudgill, 209-22. Amsterdam: John Benjamins.

— Lesley Milroy; Sue Hartley; \& David Walshaw (1994). Glottal stops and Tyneside glottalization: Competing patterns of variation and change in British English. Language Variation and Change 6:327-57.

Nielsen, Jimmi (2010). Lexical frequency effects in the spread of TH-fronting in Glaswegian: A cue to the origins of sound change? Edinburgh: University of Edinburgh MS dissertation.

R Core Team (2018). R: A language and environment for statistical computing. R Foundation for Statistical Computing, Vienna, Austria. Online: http://www.R-project.org/.

Raymond, William D.; Esther L. Brown; \& Alice F. Healy (2016). Cumulative context effects and variant lexical representations: Word use and English final t/d deletion. Language Variation and Change 28:175-202.

Roberts, Julie (1994). Acquisition of variable rules: $(-t, d)$ deletion and ing production in preschool children. Philadelphia: University of Pennsylvania $\mathrm{PhD}$ dissertation. 


\section{CALIBRATE TO INNOVATE}

(1997). Hitting a moving target: Acquisition of sound change in progress by Philadelphia children. Language Variation \& Change 9:249-66.

(1999). Going younger to do difference: Acquisition of dialect features by preschool children. University of Pennsylvania Working Papers in Linguistics 6(2), article 10. Online: https:// repository.upenn.edu/cgi/viewcontent.cgi?article $=1659 \&$ context $=$ pwpl.

Roberts, Julie, \& Wiliam Labov (1995). Learning to talk Philadelphian: Acquisition of short a by preschool children. Language Variation \& Change 7:101-12.

Romaine, Suzanne (1984). The language of children and adolescents; The acquisition of communicative competence. Oxford: Basil Blackwell.

Rosenfelder, Ingrid; Josef Fruehwald; Keelan Evanini; Scott Seyfarth; Kyle Gorman; Hilary Prichard; \& Jiahong Yuan (2014). FAVE (Forced Alignment and Vowel Extraction) Program Suite v1.2.2. Online: https://github.com/JoFrhwld/FAVE.

Sankoff, Gillian (2018). Language change across the lifespan. Annual Review of Linguistics 4(1):297-316.

(2019). Language change across the lifespan: Three trajectory types. Language 95(2):197-229.

Schleef, Erik (2013). Glottal replacement of / $t$ / in two British capitals: Effects of word frequency and morphological compositionality. Language Variation and Change 25(2):201-23.

- \& Michael Ramsammy (2013). Labio-dental fronting of / $\theta /$ in London and Edinburgh: A crossdialectal study. English Language and Linguistics 17(1):25-54.

Smith, Jennifer, Mercedes Durham, \& Liane Fortune (2007). 'Mam, ma troosers is fa'in doon!': Community, caregiver and child in the acquisition of variation in Scottish dialect. Language Variation and Change 19(1):63-99.

, \& Sophie Holmes-Elliott (2017). The unstoppable glottal: Tracking rapid change in an iconic British variable. English Language and Linguistics 22(3):323-55.

Stockwell, Robert, \& Donka Minkova (1997). On drifts and shifts. Studia Anglica Posnaniensia: An International Review of English Studies 31:283-303.

Stuart-Smith, Jane (1999). Glottals past and present: A study of T-glottalling in Glaswegian. Leeds Studies in English, 181-204. Online: https://ludos.leeds.ac.uk:443/R/-?func=dbin-jump-full\& object_id=124883\&silo_library=GEN01.

_ \& Claire Timmins (2006). 'Tell her to shut her moof': The role of the lexicon in TH-fronting in Glaswegian. In Graham Caie, Carole Hough, \& Irené Wotherspoon (eds.), The power of words: Essays in lexicography, lexicology and semantics in honour of Christian J. Kay, 171-83. Amsterdam: Rodolphi.

Tagliamonte, Sali A., \& Alexandra D’Arcy (2009). Peaks beyond phonology: Adolescence, incrementation and language change. Language 85:58-108.

Tollfree, Laura (1999). South East London English: Discrete versus continuous modelling of consonantal reduction. In Foulkes \& Docherty, 163-84.

Trudgill, Peter (1999). Norwich: Endogenous and exogenous linguistic changes. In Foulkes \& Docherty, 124-40.

Watt, Dominic, \& Lesley Milroy (1999). Variation in three Tyneside vowels: Is this dialect levelling? In Foulkes \& Docherty, 25-46.

Wells, John. C. (1982). Accents of English. Cambridge: Cambridge University Press. 
SOPHIE HOLMES-ELLIOTT

A P P E N D I C E S

APPENDIX B: lmer real time analysis of GOOSE-fronting.

\begin{tabular}{lrcrr}
\hline \hline Fixed effects & Estimate & Std. error & $t$ & $p$-value \\
\hline (Intercept) & 1893.67 & 50.41 & 37.57 & $<0.0001^{* * *}$ \\
Age: children 2016 & 86.57 & 25.04 & 14.31 & $0.00375^{* *}$ \\
Preceding environment: palatal & -268.95 & 63.92 & -4.208 & $<0.0001^{* * *}$ \\
Preceding environment: noncoronal & -131.89 & 63.89 & -2.064 & $0.041^{*}$ \\
\hline \hline
\end{tabular}

Number of observations: 1779 ; Groups: Word $(168, \mathrm{SD}=236.68)$, Speaker $(13, \mathrm{SD}=84.87)$

APPENDIX C: Imer apparent time analysis of TH-fronting (old, middle, young, and children in 2012 time point 1).

\begin{tabular}{lrrrc}
\hline \hline Fixed effects & Estimate & Std. error & z value & $p$-value \\
\hline (Intercept) & -4.98 & 1.19 & -4.19 & $<0.0001^{* * *}$ \\
Age: middle & 4.1 & 1.4 & 2.94 & $0.0033^{* *}$ \\
Age: young & 7.95 & 1.42 & 5.59 & $<0.0001^{* * *}$ \\
Age: children 2012 & 7.12 & 1.31 & 5.43 & $<0.0001^{* * *}$ \\
Gender: male & 2.09 & 0.89 & 2.35 & $0.019^{*}$ \\
Position: onset & -2.9 & 0.35 & -6.03 & $<0.0001^{* * *}$ \\
\hline \hline
\end{tabular}

Number of observations: 2592; Groups: Word $(151, \mathrm{SD}=0.93)$, Speaker $(37, \mathrm{SD}=2.47)$ 


\section{CALIBRATE TO INNOVATE}

APPENDIX D: lmer real time analysis of TH-fronting.

\begin{tabular}{lrcrc}
\hline \hline Fixed effects & Estimate & Std. error & z value & $p$-value \\
\hline (Intercept) & 2.81 & 0.62 & 4.55 & $<0.0001^{* * *}$ \\
Time point: 2016 & -1.37 & 0.62 & -2.21 & $0.03^{*}$ \\
Position: onset & -2.22 & 0.37 & -5.93 & $<0.0001^{* * *}$ \\
\hline \hline
\end{tabular}

Number of observations: 923; Groups: Word $(116, \mathrm{SD}=0.77)$, Speaker $(12, \mathrm{SD}=1.77)$

APPENDIX E: lmer analysis of style in TH-fronting in 2016 data.

\begin{tabular}{lrrrc}
\hline \hline Fixed effects & Estimate & Std. error & z value & $p$-value \\
\hline (Intercept) & 1.05 & 0.85 & 1.24 & 0.21 \\
Position: onset & -2.32 & 0.53 & -4.42 & $<0.0001^{* * *}$ \\
Style: interview & 1.13 & 0.43 & 2.12 & $<0.009^{* *}$ \\
Style: conversation & 1.65 & 0.5 & 3.3 & $0.0009^{* * *}$ \\
\hline \hline
\end{tabular}

Number of observations: 618 ; Groups: Word $(88, \mathrm{SD}=1.06)$, Speaker $(11, \mathrm{SD}=2.17)$

APPENDIX F: Imer apparent time analysis of T-glottaling (old, middle, young, and children in 2012 time point 1).

\begin{tabular}{lrrrc}
\hline \hline Fixed effects & Estimate & Std. error & $\mathrm{z}$ value & $p$-value \\
\hline (Intercept) & -2.08 & 0.82 & -2.54 & $0.011^{*}$ \\
Age: middle & 2.3 & 0.85 & 2.74 & $0.006^{* *}$ \\
Age: young & 4.5 & 0.9 & 4.99 & $<0.0001^{* * *}$ \\
Age: children 2012 & 2.28 & 0.76 & 2.99 & $0.003^{* *}$ \\
Gender: male & 1.6 & 0.57 & 2.75 & $<0.0001^{* * *}$ \\
Context: ambi vowel & -3.52 & 0.6 & -5.84 & $<0.0001^{* * *}$ \\
Context: final pause & 2.85 & 0.57 & 4.95 & $<0.0001^{* * *}$ \\
Context: final vowel & 1.79 & 0.55 & 3.25 & $0.0014^{* *}$ \\
\hline \hline
\end{tabular}

Number of observations: 2448; Groups: Word (447, SD = 1.93), Speaker (37, SD = 1.59)

APPENDIX G: lmer real time analysis of T-glottaling.

\begin{tabular}{lrrrc}
\hline \hline Fixed effects & Estimate & Std. error & $\mathrm{z}$ value & $p$-value \\
\hline (Intercept) & -0.58 & 0.82 & -0.7 & 0.48 \\
Time point: children 2016 & 1.67 & 0.68 & 2.45 & $0.014^{*}$ \\
Context: ambi vowel & -2.21 & 0.8 & -2.8 & $0.005^{* *}$ \\
Context: final pause & 4.2 & 0.87 & 4.84 & $<0.0001^{* * *}$ \\
Context: final vowel & 3.75 & 0.84 & 4.5 & $<0.0001^{* * *}$ \\
\hline \hline
\end{tabular}

Number of observations: 1623 ; Groups: Word $(307, \mathrm{SD}=2.11)$, Speaker $(13, \mathrm{SD}=1.45)$

Language in Society (2020) 
SOPHIE HOLMES-ELLIOTT

APPENDIX H: lmer analysis of style in TH-fronting in 2016 data.

(Received 23 October 2019; revision received 20 May 2020; accepted 8 June 2020; final revision received 12 June 2020)

\begin{tabular}{lrrrc}
\hline \hline Fixed effects & Estimate & Std. error & Z value & $p$-value \\
\hline (Intercept) & -0.59 & 1.1 & 0.54 & 0.59 \\
Style: interview & 0.58 & 0.31 & 1.8 & 0.06 \\
Style: reading & -4.68 & 0.55 & -8.53 & $<0.0001 * * *$ \\
Context: ambi vowel & -2.33 & 0.98 & -2.4 & $0.018^{*}$ \\
Context: final pause & 3.66 & 1.03 & 3.57 & $<0.0001^{* * *}$ \\
Context: final vowel & 3.15 & 1.01 & 3.12 & $0.002^{* *}$ \\
\hline \hline
\end{tabular}

Number of observations: 1534 ; Groups: Word $(258, \mathrm{SD}=1.8)$, Speaker $(13, \mathrm{SD}=1.97)$

Address for correspondence:

Department of Linguistics Queen Mary, University of London, E1 4NS, United Kingdom s.holmes-elliott@qmul.ac.uk 